\title{
UCLA
}

Mester

Title

La Barranca

Permalink

https://escholarship.org/uc/item/3hd6x1sd

Journal

Mester, 13(1)

Author

Piaggio, Edda

Publication Date

1984

DOI

10.5070/M3131013701

Copyright Information

Copyright 1984 by the author(s). All rights reserved unless otherwise indicated. Contact the author(s) for any necessary permissions. Learn more at https://escholarship.org/terms

Peer reviewed 


\section{La Barranca}

Me tapé la boca para no gritar cuando debí haberme tapado los oídos para no oírte. Frotaba la vista sobre la larga mesa de mármol que era tu frente donde la idea fija de mi traición to acechaba.

Me sentía con los ojos dilatados por la alegría porque había recobrado tu memoria y quería volver a verte. Fue entonces que me vino la tentación de tocar a tu puerta con el fuego en la boca y mi juventud bajo el brazo. Porque no se trataba de entregarse en el silencio ni de someterse despreocupadamente al placer bajo los párpados. Yo quería hablar cara a cara contigo primeramente para que me comprendieras y poco a poco me fueras perdonando. Sabía que en aquel corto lapso en que habíamos estado separados las medallas de confianza que tú habías colocado con orgullo sobre mi solapa habían caído. Pero sabía también-mejor dicho, suponía-que el largo corredor de ilusiones, fricciones y desdichas que durante años habíamos recorrido juntos bien podía servir para estremecerte, o, por lo menos, acercarte a mí a la vista de mi humillación y contribuir a hacer respetuoso nuestro encuentro. Me decía a mí misma que siempre hay oportunidad de volver a empezar algo.

Recuerdo que me desperté simplificada cuando aquella mañana noté que la pasión que recién acababa de vivir había llegado a su punto muerto y que no había dejado ningún rastro en mí. Con perfil romántico me quité el camisón, quitádome a la vez la pesada carga de mis orgasmos, las ilustraciones de mis placeres que habían sido frágiles como el viento y que yo bien podía en aquel momento, liberada, evocar con asco o con una complaciente alegría indiferente.

De pronto me vino a la memoria el recuerdo de la casita que habíamos alquilado durante el primer año de casados. Me trajo alivio. Era como limpiar con un rastrillo la alfombra mágica que me había arrastrado a aquellos sueños absurdos e irresponsabilidades. Me parecía estar oyendo el silbido estridente de las martinetas que venían desde el patio del vecino para colocarse en el antepecho de nuestra ventana cuando la dejábamos abierta en las noches de plenilunio para mejor mirarnos al hacer el amor. Recordé también la cocina vieja donde tú estarías tomando el desayuno a aquellas horas, entre platos astillados de porcelana Olmos, aquella cocina simpática y grasienta que había sido no solamente testigo de nuestra costumbre, de nuestro enmohecido aburrimiento, sino una forma de realidad triste que habíamos generado junto y que por ser tan nuestrapensaba yo - no se resignaría fácilmente a vernos separados.

Fue así que bajo mi grueso tapado me abalanzaba sobre el invierno para poder recuperarte. Pero la suerte estaba dada y yo no lo sabía. Ignoraba que te resultaría imposible oírme y mucho menos entenderme porque para poder oír y entender hay que ser libre y tú no lo eras, maniatado como estabas por el recuerdo de nuestro último diálogo y de mi decisión irrevocable de aquel día célebre cuando te dije adiós. 
Se abrió la puerta y me miraste. Dos espasas arrugas cruzaban tus mejillas. Tuve la sensación de haberme equivocado de piso y retrocedí en aquel corredor oscuro hasta llega a la escalera donde me apoyé sobre el barandal. La luz automática se apagó repentinamente mientras la indiferente luna bailaba sobre tus brazos enfurecidos y la pared se agitaba al ritmo de tu sombra.

Con la presión de tu mano sobre mis dientes me mordí la lengua, y lo peor fue que nunca más pude abrir la boca, esa boca que hubiera querido mover para hablar, escupir y maldecirte antes de perderme en el espacioso canal de la muerte donde, enredada en mi odio hacia ti, mis suspiros e impaciencias, con tu puñal en mi pecho y mi historia de hechizo en las manos, después de 20 siglos de espera, no sé si tengo condena o redención.

\section{Edda Piaggio}

Edda Piaggio nació en Uruguay, en la ciudad dde Montevideo y desde muy joven se dedicó a las letras. En 1972 recibió el Premio del Ministerio de Educación y Cultura por su poemario Llanuras rituales, de acentos profundos y estilo barroco, ajustado más bien a preocupaciones metafísicas. En 1977 publicó su segundo libro Complementos y un año después tradujo Atalaya de Piedra y Bodas de Arena de la escritora francesa Gil Pasteur. En 1982 dio a conocer su última obra de poesías Ciruelo Rojo Vivo; expresada a través de un lenguaje muy íntimo y simple, alcanza lo universal y lo cósmico.

Edda Piaggio ha escrito además varios cuentos; uno de ellos 'El Paraíso' fue recientemente premiado por la revista Garcín. 